\title{
COMPLIANCE E GESTÃO DE CRISE
}

DA COVID-19: POLÍTICA

REGULATÓRIA E RECONSTRUÇÃO

SOCIAL PÓS-CONFLITO

Eduardo Saad Diniz ${ }^{1}$

Mariana Urban ${ }^{2}$

\author{
COVID-19 CRISIS MANAGEMENT IN BRAZIL: \\ REGULATION, COMPLIANCE AND POST-CONFLICT \\ SOCIAL RECONSTRUCTION
}

RESUMO: O texto dedica-se ao estudo dos desafios do controle social em face da crise da COVID-19, com delimitação nas possibilidades de utilização de recursos de compliance para a gestão de crise e reconstrução social pós-conflito. A crise é situada em um contexto de regressão da política regulatória, analisando suas consequências no âmbito sanitário e econômico. O uso dos recursos de compliance é pensado a partir da normalização de estado permanente de crise, necessidade de priorização dos recursos e desenvolvimento de estratégias de recondução da cadeia produtiva em torno do que é essencial. O texto trabalha com o método dedutivo e com a organização do discurso na área.

Palavras-chave: Compliance. Gestão de crise. Política regulatória. Reconstrução social pós-conflito. COVID-19.
ABSTRACT: This essay aims to study the challenges of social control in face of the COVID-19 crisis, setting out the possibilities of using compliance resources for crisis management and post-conflict social reconstruction. The crisis is discussed in a context of a regulatory rollback policy, analyzing its consequences in the health and economic spheres. The use of compliance resources is designed based on the normalization of a permanent state of crisis, the need to prioritize resources and the development of strategies for renewing the supply chain around what is essential. The essay was written based on the deductive method and with the organization of the discurse in the research topic.

Keywords: Compliance. Crisis management. Regulatory policy. Post-conflict social reconstruction. COVID-19.

\footnotetext{
${ }^{1}$ Professor da Faculdade de Direito de Ribeirão Preto e do Programa de Integração da América Latina da Universidade de São Paulo (FDRP/PROLAM/USP). Senior Fellow Carol and Lawrence Zicklin Center for Business Ethics Research, The Wharton School, Universidade da Pennsilvânia, EUA; Livre-Docente em Criminologia pela FDRP/USP (2018) Doutor em Direito pela Universidade de São Paulo (2006-2010) e Doutor em Direito pela Universidade de Sevilha, Espanha (2017); Bolsista Produtividade CNPQ-PQ2 (2017-2020) Bolsista FAPESP na Universidade da Pennsilvânia, EUA (2017); Bolsista Doutorado Sanduíche DAAD/Capes na Universidade de Regensburg, Alemanha (2009-2010).

${ }^{2}$ Graduanda em Direito pela USP.
} 


\section{INTRODUÇÃO}

A pandemia da COVID-19 atingiu em cheio o senso comum: "nunca houve tanto conhecimento sobre o que não conhecemos" (HABERMAS, 2020). A retórica constante da "desglobalização", do fechamento de fronteiras, e a ansiedade para manter estável a performance econômica - como se ela fosse um impeditivo da proteção contra a contaminação global - trouxeram novos problemas que demandam novas soluções. A polarização do debate afetou precisamente o que se entende por controle social e suas repercussões nas interações sociais. Yuval Harari foi dos primeiros a pensar sobre os efeitos da pandemia no controle - e em nossas vidas -, e a incitar o mundo a refletir sobre o "teste de cidadania" provocado pela tensão entre a "vigilância totalitária" (totalitarian surveillance) e o "empoderamento da cidadania" (citizen empowerment ${ }^{3}$. Harari prenunciou a transição do controle "sob a pele" (over the skin) para o controle "sobre a pele" (under the skin) e defendeu o empoderamento e a informação adequada às pessoas, de tal forma a cultivar o senso de motivação e cooperação (HARARI, 2020). Byung-Chul Han, a seu modo, produziu inteligente ensaio sobre a biopolítica digital que acompanha a psicopolítica digital e seu impacto no exercício ativo do controle. Byung-Chul Han enfatiza que o uso de máscaras e estratégias de controle, em verdade, permite evidenciar um melhor tratamento da "emergência viral". Com alguma sensibilidade ao contexto, é bastante provocativo ao acentuar que as tradições orientais são "menos resistentes e mais obedientes que na Europa", o que impactaria significativamente na melhor performance de controle da COVID-19: a "vigilância digital salva vidas humanas e o cidadão é avaliado conforme seu papel na sociedade" (HAN, 2020). No fim das contas, o que mais interessa é a consolidação de um modelo de Estado que domina as informações sobre as interações sociais (HAN, 2020).

\footnotetext{
3 "Many short-term emergency measures will become a fixture of life. That is the nature of emergencies. They fastfoward historical processes. Decisions that in normal times could take years of deliberatoin are passed in a matter of hours. Immature and even dangerous technologies are pressed into service, because the risks of doing nothing are bigger. Entire countries serve as guinea-pigs in large- scale social experiments. What happens when everybody works from home and communicates only at a distance? What happens when entire schools and universities go online? In normal times, governments, businesses and educational boards would never agree to conduct such experiments. But these aren't normal times" (HARARI, 2020).
} 
Esta disputa teórica talvez seja interessante para observar as experiências asiáticas e europeias. Ela não necessariamente se confirma no caso americano. E, apesar das afinidades em termos de "regressão regulatória" (regulatory rollback) e da necropolítica da pandemia entre Norte e Sul ${ }^{4}$, a experiência norte-americana tampouco permite entender as dificuldades de se lidar com comunidades altamente carentes e vulneráveis, não ao menos com a profundidade dos contextos periféricos da América Latina. Para dizer a verdade, o referencial biopolítico ou a maior ou menor coerência entre controle e liberdades pessoais não interessa muito mais do que como um referencial explicativo (HAASS, 2020). A pandemia é um problema novo que demanda novas soluções para o exercício do controle social, e varia sensivelmente conforme o contexto.

Neste texto, o que se pretende é explorar as possibilidades sobre a gestão da crise da COVID-19, e como, diante da baixa densidade da política regulatória no Brasil, questionar o papel das iniciativas de controle do setor privado, encontrando sua delimitação em soluções inovadoras de reconstrução social pós-conflito a partir do emprego dos recursos de compliance. Dadas as dimensões da pandemia, é necessário reavaliar o lugar do setor privado, das multinacionais e empresas líderes no mercado nacional sobretudo, o que se considera "recuperação sustentável" (sustainable recovery) (STIGLITZ, 2020). Impressiona, no entanto, o imediatismo na proteção do interesse dos acionistas e impressiona ainda mais negativamente como a produção científica sobre a crise da COVID-19 oferece tão poucas soluções quanto ao uso de recursos privados para fins de reconstrução social pós-pandemia. O que se trata aqui é de uma revisão ética da noção de custo das assimetrias sociais e da forma como a relação entre privado e social pode reestruturar normativamente a solidariedade na sociedade, com o propósito de explorar o tipo de liderança do setor privado de que fato necessitamos (OCAMPO; FACCIO, 2020).

Apesar disso, não faltam análises sobre o papel dos programas de compliance para a gestão da crise da COVID-19, cuja imaginação não vai para muito além da averiguação da regularidade de doações, filantropia, distribuição de máscaras, álcool gel e testes de

\footnotetext{
${ }^{4}$ Para mais informações sobre regulatory rollback: Michalowski e Brown (2019, p. 90-115) e Friedrichs e Rothe (2020, p. 95-102).
} 
contaminação, ou, o que é ainda pior, a discussão sobre novas técnicas de treinamentos online ou "pílulas do comportamento ético" na empresa. Estudo recente conduzido pela KPMG, inclusive, demonstra que a gestão de crise dizia respeito mais a "riscos emergentes" (avaliação e monitoramento das transações de doações, trabalho remoto, terceiros e renegociação de contratos e covenants, relacionamento com agentes públicos, comitê de crise para monitoramento de novo arcabouço regulatório, saúde das pessoas e fraudes digitais e privacidade dos dados), sem que a preparação para a normalidade de crises e a reconstrução social pós-conflito sequer tenham sido mencionadas (KPMG, 2020). As iniciativas corporativas acabam se reduzindo a medidas de planejamento e reorganização interna do ambiente empresarial, e isso é muito pouco. Mesmo que sequer tenhamos maior clareza sobre a produção de evidências científicas sobre a "efetividade" dos programas de compliance, ou sequer de sua "necessidade" (como justificar os custos de compliance em tempos de escassez de recursos, desmanche da cadeia produtiva e arrefecimento da economia global, estas iniciativas não poderiam representar melhor o surgimento de uma nova retórica de compliance.

É verdade que não há precedente moderno sobre o uso de recursos de compliance para gestão de crise nesta magnitude. O que se tem é apenas uma resolução teórica de que a gestão de crise deve integrar-se a um tratamento mais adequado da crise sanitária e econômica, de tal forma a desenvolver capacidades para a utilização de recursos corporativos para orientar a cadeia de produção do que é realmente essencial, protegendo a integridade das estruturas de mercado e das redes contratuais. Em função deste contexto, este ensaio será estruturado em três partes principais: 1) avaliação da escalada da crise do Covid-19 no cenário político-econômico brasileiro, onde serão abordados os principais impactos do Covid-19 na política regulatória sanitária e econômica no Brasil; 2) análise do papel do setor privado diante da insuficiência da política regulatória; 3) estudo das possibilidades de gestão de crise e utilização dos recursos de compliance para a reconstrução social pós-conflito. 


\section{A ESCALADA DA COVID-19 NO BRASIL}

Em abril de 2020, a equipe de análise do Covid-19 do Imperial College de Londres demonstrou em seu levantamento de dados que, dentre os 48 países analisados, o Brasil teria a maior taxa de transmissão do Covid-19 (IMPERIAL COLLEGE OF LONDON COVID-19 RESPONSE TEAM, 2020), confirmado também pela base de dados Johns Hopkins (CORONA VIRUS RESOURCE CENTER, 2020). Desde que confirmado o primeiro caso em 26 de fevereiro de 2020 (AQUINO; MONTEIRO, 2020) ${ }^{5}$, o Governo Federal vem buscando a aplicação de medidas de contenção nos estados brasileiros por meio do federalismo regulatório. Dentre as questões endereçadas, cabe destacar as restrições de viagens, impostos, demissões em massa, linhas de crédito, restrições de abertura, distanciamento social e auxílio financeiro.

Apesar disso, o que se vê é uma mistura de sinais incoerentes vindos do Governo Federal quanto à gravidade do surto no Brasil, transformando a questão sanitária em um debate político de alto custo moral e social. Enquanto uma parte significativa da população estava preocupada com os impactos potenciais do surto no Brasil (PIRES, 2020), a resposta do Governo Federal foi uma disputa interna dentro do governo Bolsonaro, o que levou a uma crise política mais intensa. Inspirada na forte retórica negacionista de Bolsonaro (RICARD; MEDEIROS, 2020), que se referiu ao Covid-19 como uma "gripezinha" (URIBE et al., 2020) e se recusou a cumprir as diretrizes da Organização Mundial da Saúde (CARAM et al., 2020), essa disputa interna levou ao atraso na implementação de medidas regulatórias federais mais coerentes no sistema de saúde e aumentou a instabilidade política em curso. Desde então, o Brasil passou não só a enfrentar uma crise política, mas também a suportar um processo generalizado de politização das crises sanitária e econômica ${ }^{6}$.

O Ministério da Saúde, à época liderado pelo ministro Luiz Henrique Mandetta, defendia um quadro rigoroso de distanciamento social. A estratégia foi adotada com

\footnotetext{
${ }^{5}$ Apesar disso, estudos mais recentes estimem que o vírus já estivesse circulando no Brasil no início de fevereiro (DELATORRE et al., 2020).

${ }^{6}$ Como apontado supra, atribui-se parte da politização da crise do coronavírus no Brasil ao alinhamento político com o governo Trump e a atual política de embate dos Estados Unidos contra a China. A politização atribuindo a culpa do vírus à China como uma manobra político-econômica ocupou espaço nos discursos de membros associados ao governo federal tanto nos Estados Unidos quanto no Brasil, pelos quais se pode constatar uma atitude xenofóbica ao se caracterizar o coronavírus como "vírus chinês" (PAULINO, 2020, p. 161-181).
} 
sucesso pela maioria dos países e recomendada pela Organização Mundial da Saúde. Em contrapartida, alinhando-se aos padrões de regressão regulatória da gestão Trump, o presidente brasileiro, Jair Bolsonaro, adotou uma postura de mitigação dos potenciais impactos da pandemia (PHILLIPS, 2020), ignorando descobertas científicas que eram contra suas crenças e estando mais preocupado com a recessão econômica do que com a disseminação do vírus. A disputa interna dentro do Governo Federal levou à demissão do Ministro da Saúde (SHALDERS, 2020) e, menos de um mês depois, à renúncia de seu sucessor, Nelson Teich (AGOSTINE et al., 2020).

Essa postura vem provocando respostas negativas da população e da comunidade internacional, o que intensificou ainda mais os atritos entre Bolsonaro e a mídia (GARCIA, 2020) e levou a certa resistência por parte dos governos estaduais para cumprirem integralmente com as diretrizes federais (PHILLIPS, 2020). Nesse contexto, a Diretoria de Análise de Políticas Públicas (Dapp) da Fundação Getúlio Vargas (FGV) concluiu em uma análise do panorama atual que os governadores estaduais se tornaram os principais adversários políticos de Bolsonaro em relação a quais medidas devem ser usadas no enfrentamento à pandemia (SHALDERS, 2020). Conforme indicado pela Fundação Oswaldo Cruz (Fiocruz) em sua análise das gestões de riscos e governança quanto ao Covid-19 (FREITAS, 2020), há indícios de que a falta de uma ação coordenada do governo federal com os estados e municípios evidencia uma redução na efetividade do combate ao Covid19 no Brasil.

O Brasil tem um relevante histórico de combate a doenças e epidemias. No início do século XX, figuras públicas brasileiras como Oswaldo Cruz e Carlos Chagas tornaram-se referência no tratamento de um rol de surtos, tais quais malária, febre amarela, varíola, leptospirose e, não por acaso, a doença de Chagas. Na década de 80, o Brasil desenvolveu uma resposta contra o HIV/AIDS (SOUZA et al., 2020, p. 23-26; OMS, 2020) que se tornou um modelo aplicável a outras regiões, como em vários países da África. O Brasil foi um dos primeiros países fora da OCDE (Organização para Cooperação e Desenvolvimento Econômico) a implementar o direito constitucional à cobertura universal da saúde do Sistema Único de Saúde (SNS). O Programa Nacional de Imunização disponível por meio do Sistema Nacional de Saúde é conhecido mundialmente, e o Brasil foi capaz de liderar 
pesquisas relevantes e conter o surto de Zika vírus há alguns anos atrás (MAIEROVITCH; VASQUEZ, 2018, p. 174-185). Ainda assim, estamos tendo uma das piores respostas entre todos os países afetados pela Covid-19 e já nos tornamos o novo epicentro da pandemia.

\subsection{A fragilidade da política regulatória}

É certo que a pandemia da Covid-19 é sem precedentes nos tempos modernos, e talvez ainda seja cedo para traçar um panorama das consequências socioeconômicas que o Brasil e o mundo enfrentarão nos próximos anos. Contudo, acredita-se ser seguro já afirmar que, impulsionado pela instabilidade política e falta de coordenação entre os entes federativos, o Brasil atualmente enfrenta duas grandes crises devido à falta de excelência regulatória: a crise sanitária e a crise econômica.

Pode-se dizer que a fragilidade política e regulatória do Brasil permitiu que a instabilidade sanitária já esperada de uma pandemia se alastrasse pelo sistema de saúde a ponto de se configurar uma crise sanitária. Ainda na condição de um país em recuperação da crise econômica antecedente, o Covid-19 causou impactos econômicos globais, e, particularmente no Brasil, de forma ainda mais acentuada como consequência direta da inabilidade de contenção da disseminação do vírus. Neste tópico, serão analisados os aspectos sanitários e econômicos da política regulatória brasileira em face da Covid-19.

\subsubsection{Política regulatória e crise sanitária}

Por meio de uma revisão crítica das políticas públicas neoliberais (BORLINI, 2020, p. 321-333; BRAVO, 2011; MENDES, 2012), reconhece-se que as estruturas da saúde pública brasileira já vinham sendo desmontadas antes mesmo da pandemia do Covid-19 em uma tendência de regressão regulatória. O início de um processo do que correntes críticas do governo chamam de "contrarreforma do Estado" (BEHRING, 2003; SILVA, 2003; SOARES, 2013, p. 91-114; OLIVEIRA, 2011, p. 132-146) demonstrou-se presente nas políticas neoliberais de privatização e descentralização para reduzir os esforços da máquina pública nas estruturas de determinados serviços básicos, como educação, saúde e cultura (NORONHA; SOARES, 2001, p. 455-450). Apesar de um longo histórico de subfinanciamento, a abordagem política de desinvestimentos nos serviços sociais atingiu de forma ainda mais 
significativa o Sistema Único de Saúde, que, fruto do Movimento Sanitário da fase de pré-

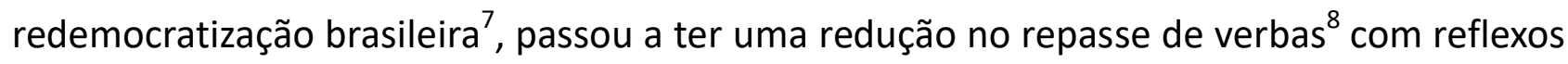
diretos no acesso à atenção em saúde (AMARAL, 2019).

Se já havia debates sobre como proteger e aprimorar o Sistema Único de Saúde antes da pandemia (SOUZA, 2019, p. 74), os impactos da Covid-19 acentuaram as dificuldades pré-existentes e impuseram novos desafios para a saúde pública brasileira. Em 11 de março de 2020, a Organização Mundial da Saúde classificou o caso como uma pandemia que poderia impactar profundamente o cuidado com a saúde na maioria dos países. Apesar da descrença inicial quanto aos efeitos do vírus no Brasil durante o mês de fevereiro, a atenção à disseminação escalou rapidamente durante a primeira quinzena de março, quando o discurso de quarentena voluntária e a imposição de medidas restritivas de isolamento social passaram a ser pauta no Brasil - sobretudo na cidade de São Paulo, o epicentro inicial do vírus no país.

Por ser um vírus de imunidade ainda inexistente, a preocupação passada pelas diretrizes mundiais era o risco de se perder o controle da expansão e do índice de contaminação, o que, por conseguinte, dificultaria o processo de contenção de casos e respectivo alívio das vagas nas unidades de terapia intensiva. Para evitar um colapso nas redes de saúde pública e privada, os padrões regulatórios (regulatory standards) globais eram a priorização da testagem como principal estratégia de monitoramento da taxa $\mathrm{R}_{0}{ }^{9}$ na fase inicial da disseminação da Covid-19. No entanto, o Brasil reagiu tarde a pilar da prevenção e logo de início se deparou com um grave caso de subnotificação por conta da falta de testes. Ao final de abril, dois meses após o vírus se espalhar pelo Brasil, a testagem estava por volta de menos de mil pessoas a cada milhão de habitantes, enquanto, na mesma época, os Estados Unidos testavam 13 mil pessoas a cada milhão de habitantes. De

\footnotetext{
7 "(...) a partir de 1986, o movimento sanitário havia assumido um caráter inovador e uma prática política alternativa, centrada na luta pela democratização do Estado e na formulação de um projeto contra-hegemônico direcionado à ampliação da consciência sanitária e do direito à saúde, que visava à reconstrução da sociedade em novas bases" (PAIVA; TEIXEIRA, 2014, p. 15-35).

8 "Desde que a Emenda Constitucional (EC) 95 foi aprovada, em dezembro de 2016, o orçamento para a Saúde tem diminuído cada vez mais. Somente em 2019, a perda de investimentos na área representou R\$ 20 bilhões, o que significa, na prática, a desvinculação do gasto mínimo de 15\% da receita da União com a Saúde" (CNS, 2020).

${ }^{9}$ Em 16 de março, o diretor-geral da Organização Mundial da Saúde afirmou em coletiva de imprensa que "a nossa principal mensagem é: testem, testem, testem" (tradução livre) (BBC, 2020).
} 
forma similar, na Europa a Espanha testava 19,9 mil e a Alemanha, 24,7 mil. Na América Latina, o Chile testava 6,7 mil; e o Uruguai, 4,2 mil por milhão de habitante.

A dificuldade de acesso inicial aos testes em massa e a resposta tardia do Brasil na implementação de uma política unificada de contenção e isolamento social logo de início provocaram uma contaminação progressiva que, em 30 de julho de 2020, resultava em 91.263 mortes contabilizadas e mais de 2,6 milhões de casos registrados (NYT, 2020). Cabe destacar que, em razão do grave cenário de subnotificação, estima-se que os números oficialmente notificados no Brasil sejam menos que $10 \%$ dos números reais, e que, portanto, não são precisos (ALVES, 2020). Da mesma forma, as estratégias de regulação privada das empresas brasileiras dominantes foram impulsionadas por medidas profiláticas. Neste contexto, a insuficiência de recursos na cadeia de suprimentos e as mudanças repentinas na demanda do mercado final motivaram as empresas a reestruturar o mercado brasileiro de forma que a produção de recursos profiláticos aumentasse significativamente. Essas são alternativas frágeis para a melhoria institucional que não refletem a gestão de crises. Sabendo desde o início que o Brasil não teria capacidade para distribuir testes suficientes, o Ministério da Saúde deveria ter implementado um sistema de rastreamento de contatos e isolamento seletivo, como foi feito pelo Vietnã (BBC, 2020). Neste contexto, o estado americano de Massachusetts está atualmente implementando uma rede de detetives de saúde pública para rastrear novos casos de Covid-19 (NYT, 2020). Da mesma forma, o principal pilar de atenção do sistema de saúde brasileiro conta com o Programa de Agentes Comunitários de Saúde ${ }^{10}$ desde 1991.

\subsubsection{Política regulatória e crise econômica}

Em 13 de maio de 2020, o Ministério da Economia divulgou uma Nota Informativa com a avaliação de que os impactos econômicos da Covid-19 estariam "diretamente relacionados à determinação do isolamento social", e que poderiam ser divididos em: "(i) impacto imediato diante das restrições à produção e ao consumo; (ii) duração do período

\footnotetext{
${ }^{10} \mathrm{O}$ papel dos agentes comunitários de saúde é acompanhar as condições locais de saúde e monitorar as doenças e áreas de risco nas comunidades. O programa poderia ter sido um fator chave na prevenção contra a Covid-19, mas as medidas regulatórias do Ministério da Saúde abordaram tarefas mínimas e não exploraram todo o potencial desses agentes.
} 
de recuperação; e (iii) impacto sobre a trajetória de longo-prazo da economia" (MINISTÉRIO DA ECONOMIA, 2020). A preocupação de que o isolamento social seria a causa do colapso econômico tem sido uma bandeira determinante do governo federal, que, inclusive, capitaneou parte significante da crise política entre o governo federal, os governadores estaduais e a composição inicial do Ministério da Saúde.

O debate sobre os impactos da Covid-19 na economia apresenta, portanto, duas vertentes que são, ao final, correlacionadas: (i) o impacto na população em geral e (ii) o impacto na indústria. Para a população, a principal ameaça econômica da Covid-19 demonstrou-se ser principalmente o desemprego e, como consequência, a incerteza sobre fonte de renda e subsistência. De acordo com o Instituto Brasileiro de Geografia e Estatística (IBGE), a informalidade representa mais que $40 \%$ do mercado de trabalho brasileiro (PESSANHA, 2020). Para essa parte da população, a realidade do trabalho os exime de qualquer mecanismo de proteção social devido à ausência de vínculos empregatícios formais. Não obstante, trabalhos informais geralmente requerem a exposição do trabalhador ao contato humano - algo inviabilizado com o advento da Covid19. Ainda que tenha havido algum esforço por parte do governo federal para distribuição de auxílio financeiro a essa parcela da população, a realidade é que muitos se depararam com a escolha (ou ausência de) ter que abdicar da segurança da proteção contra a Covid-19 para assegurar uma renda familiar mínima, como, por exemplo, por meio de trabalhos de delivery de aplicativos (FONSECA, 2020). O mercado de trabalho formal também sofreu um grande impacto. Até o mês de maio, 7,8 milhões de postos de trabalho no Brasil haviam sido extintos, e, em junho, o IBGE relatou que, pela primeira vez, menos da metade das pessoas em idade para trabalhar estava empregada (GARCIA, 2020). Em realidade, o desemprego causado pela Covid-19 foi global, e a flexibilização nas legislações trabalhistas dos respectivos países e a consequente facilidade para as demissões se refletiu nos índices de desemprego globais. No setor privado, o impacto negativo afeta, sobretudo, os índices de marginalização e vulneração das liberdades pessoais no ambiente laboral, inclusive fazendo exacerbar a situação de redução a condição análoga à de escravo ou "escravidão moderna" (modern slavery) (TRAUTRIMS, 2020, p. 1-6). 
As demissões em massa foram um reflexo da crise financeira enfrentada por parcela significativa das empresas no Brasil, que, acompanhando as tendências globais, tiveram dificuldade em se sustentar durante o atual cenário econômico. Em junho de 2019, a variação cumulada em 12 meses de pedidos de recuperações judiciais havia sido de $(18,4 \%)$, e de falências (14,8\%). Já em junho de 2020, a variação cumulada de pedidos de recuperações judiciais atingiu a marca de $28.2 \%$, e, de falências, $28.4 \%$ (SCPC, 2020). Esses números refletem uma alta significativa no número de empresas brasileiras que recorreram ao judiciário para buscar auxílio à sua sobrevivência. Já em relação às indústrias, a Covid-19 exigiu que as empresas implementassem esforços para trabalho remoto de forma urgente e até mesmo improvisada. O reflexo dessa onda de incertezas foi claramente transparente nos impactos da Covid-19 no mercado financeiro: em questão de dias, a Bovespa se deparou com um recorde de circuit breakers quase consecutivos (FERREIRA et al., 2020), e uma queda expressiva refletindo em questão de dias os danos causados no decorrer de meses no período da Grande Depressão de 1929.

Durante a pandemia, a saúde pública e a economia vêm sendo colocadas como antagonistas, circundadas de um intenso debate sobre priorização ou justaposição entre ambos. Em um cenário de crise sem precedentes, caberia à Administração Pública assegurar a subsistência da população vulnerável enquanto busca conter a disseminação do vírus o mais rápido o possível - para que, na mesma velocidade, a "normalidade" pudesse ser retomada (KRUEGER, 2020). O mais interessante de tudo, no entanto, é que a centralidade das empresas, sobretudo por força da escassez de recursos no contexto da crise, é negligenciada. A gestão de crise deveria tomar por pressuposto como a recondução da cadeia de produção em torno do que é essencial poderia facilitar a gestão de crise em escala global.

\subsubsection{Os problemas do negacionismo}

Em 15 de abril de 2020, o Supremo Tribunal Federal reforçou o entendimento de que as medidas impostas pelo governo federal no combate ao Covid-19 não afastam a competência concorrente dos estados, municípios e Distrito Federal de tomarem outras providências normativas e administrativas. A decisão foi expressa no referendo da medida 
cautelar que havia sido deferida em março no julgamento da Ação Direta de Inconstitucionalidade 6341, que discutia um eventual conflito de competências a partir das medidas adotadas pelo governo federal na Medida Provisória 926/2020 ao se determinar a essencialidade dos serviços públicos. A partir da decisão que buscou resguardar a autonomia dos estados, municípios e Distrito Federal de também legislar sobre as regras de isolamento social e atividades essenciais que devem permanecer em funcionamento na quarentena, nota-se um certo afastamento por parte do governo federal na implementação de medidas de combate ao Covid-19. Afastamento, inclusive, blindado por um discurso distorcido por parte de Bolsonaro de que o STF havia decidido que a responsabilidade de implementar ações de combate ao Covid-19 seria dos estados e municípios, e não do governo federal (D’AGOSTINO, 2020).

Como resistência contra as diretrizes menos genéricas anunciadas pelo Governo Bolsonaro, os governadores estaduais optaram por não cumprir com o federalismo regulatório (IGLESIAS; ADGHIRNI, 2020). Como resultado, as medidas se regionalizaram com uma disputa contínua por recursos em todo o país. Embora os governadores e prefeitos tenham se tornado essenciais para conter os impactos da pandemia no Brasil, a desconsideração do federalismo regulatório e a conseqüente implementação local de medidas estão comprometendo o efetivo monitoramento e controle pela população dos investimentos para conter os impactos da pandemia. A primeira investigação midiática da Polícia Federal neste contexto foi a Operação Placebo (KADANUS, 2020), que analisou o possível envolvimento do Governador do Rio de Janeiro em um esquema de corrupção que precificou demais a implementação de projetos contra a Covid-19, incluindo a construção de hospitais de campanha de emergência no estado. Desde então, outras investigações relacionadas com a aplicação da lei começaram a surgir em todo o país.

A análise empírica da experiência internacional demonstra que os países com os melhores índices de recuperação do Covid-19 foram aqueles que suspenderam a normalidade da dinâmica social (REN, 2020). Como a paralização das atividades econômicas implica em uma redução da atividade produtiva nacional e um consequente impacto econômico, ao delegar a implementação das medidas restritivas de isolamento social aos governos locais e manter um discurso pró-economia, o governo federal cria 
mecanismos para delegar a culpa das consequências econômicas pelas medidas restritivas aos governadores e prefeitos, eximindo-se de uma eventual culpa pela recessão econômica pós-Covid-19.

Talvez pela instabilidade interna causada pela liderança inspirada por dinâmicas autoritárias e um forte senso de indiferença moral contra os custos sociais e morais da pandemia, ou talvez devido às restrições que Bolsonaro vem impondo a seus ministros, o Ministério da Saúde não está sendo protagonista nas medidas implementadas contra a Covid-19. Após as discussões em andamento sobre a cloroquina, as medidas regulatórias sobre saúde tornaram-se mais focadas no tratamento do que na prevenção do vírus. Desta forma, em uma análise quantitativa, é possível perceber que uma maior quantidade de medidas relevantes divulgadas no relatório diário do governo federal, disponibilizado no portal da Casa Civil relatam liberação de recursos e repasse de verbas - o que traduz em uma baixa atuação ativa no combate à Covid-19 e implementação de politicas públicas. Fora os repasses de verbas, as medidas regulatórias implementadas pelo Governo Federal estiveram geralmente relacionadas aos impactos econômicos e restrições de fronteiras, abrangendo medidas administrativas, assistenciais e econômicas ${ }^{11}$.

O problema maior é cumplicidade do setor privado, reproduzindo a postura negacionista sobre a gravidade do vírus, o que, como não poderia deixar de ser, exerce influência considerável na articulação das estratégias de controle e regulação privada. É bem possível afirmar certa omissão por parte das políticas regulatórias em buscar uma coordenação nacional e implementação de medidas efetivas ao combate da Covid-19. Ao delegar a responsabilidade de implementação de medidas contra a Covid-19 aos governos locais e manter sua atuação no plano do discurso, utilizando-se por base uma distorção da decisão proferida pelo STF, a política regulatória busca se afastar de uma correlação entre

\footnotetext{
${ }^{11}$ Algumas das medidas administrativas relevantes incluíram o reconhecimento do estado de calamidade pública no Brasil, que impactou o cumprimento da meta de saldo primário fiscal para o ano; a implementação de restrições de viagens e fronteiras; e a alteração no calendário de licitações e planejamentos públicos. Quanto às medidas assistenciais, merece destaque a implementação de linhas de crédito, em especial aos setores mais afetados e pequenos empreendedores; e programas limitados de auxílio social. Já em relação às medidas econômicas, destaca-se o aumento de liquidez por meio da injeção monetária por parte do Banco Central; e alteração das leis trabalhistas e tributárias, as quais foram objetos de críticas por configurarem, respectivamente, uma possível violação dos direitos socioeconômicos e antecipação de alterações já em vista com a reforma tributária. As medidas podem ser conferidas na íntegra nos relatórios diários disponibilizados no portal da Casa Civil (2020). Mais sobre: Sant'Ana (2020) e Anamatra (2020).
} 
as consequências do Covid-19 e sua administração, indiferente à falta de transparência no repasse de verbas, notadamente no setor bancário (THE INTERCEPT, 2020).

\section{GESTÃO DE CRISE E COMPLIANCE}

Acredita-se que os programas de compliance tenham por objeto restrito a adesão a padrões regulatórios. Isso pressupõe, como mínimo, que as empresas sejam fórmulas fechadas e que suas estruturas não estejam abertas à aprendizagem organizacional. Fala-se em atribuição de responsabilidade por falha nos programas de compliance ("déficit de organização") (TIEDEMANN, 2012, p. 495-512), o que pressupõe o funcionamento perfeito ou adequado dos sistemas de gestão. Bem ao contrário, compliance pressupõe o erro e as possibilidades de aprendizagem e é precisamente aí que operam as estratégias de gestão de crise, antecipando-se a possíveis erros e demonstrando sua maior ou menor capacidade de reagir diante deles.

Agora, a diferença é que a crise da COVID-19 traz a necessidade de que sejam desenvolvidas estratégias de controle voltadas à "preparação" (readiness) para um estado permanente de crise, que impacta nas condições sanitárias e econômicas da sociedade, no que se conhece como "avaliação de preparação" (readiness assessment) ${ }^{12}$. Não se trata mais de estar preparado para gerir erro ou um desastre. Esta preparação diz respeito ao estado de permanente necessidade de recondução da cadeia de produção ao que é realmente essencial. A disciplina científica da gestão de crise da COVID-19 impõe às funções de compliance a capacidade de planejamento estratégico e de atribuição de responsabilidade conforme à priorização de recursos e geração de oportunidade ética e sustentável de negócios. A gestão de crise indica que se conhece a dinâmica das interações sociais, para além daquilo que se prevê ou não na política regulatória. Para além do cálculo

\footnotetext{
12 "On an organization-by-organization level, there will be those that adopt a risk-based approach to transition and transform their organizations to thrive in the new normal. As Winston Churchill once reportedly said, "No crisis should go to waste." That is what happened during the disruption to air travel after the World Trade Center attacks on September 11, 2001. Airports that used risk management strategies were able to transform their transportation mission to include entertainment centers for travelers who needed to be two hours earlier than their flights. They redesigned airport terminals to have a vast array of restaurants, shopping and entertainment options behind security that did not exist before. This led to the creation of new revenue streams. In the same way, after the financial crisis of 2008 , banks that had used risk management to diversify operations with new fee-based services were able to thrive by replacing the revenues lost from interest income" (KNOWLEDGE AT WHARTON, 2020).
} 
utilitário (comportamento racional, conforme custo e benefício e imediatismo do interesse dos acionistas), demonstra que o comportamento ético das corporações radica em sua capacidade de conduzir a produção para o comportamento pró-social, estruturando normativamente a sociedade em torno da reconstrução social pós-conflito.

A partir da crise da COVID-19, não se trata apenas de pressupor que os programas de compliance falham e que, como consequência natural, deveriam dispor de estratégias para lidar com o erro. É preciso desenvolver habilidades para internalização da crise na gestão empresarial. Com a retração da capacidade produtiva, o aumento vertiginoso das taxas de desemprego, fraudes, contratações emergenciais irregulares, descontrole das exportações e desmanche da cadeia global, a pandemia opera como uma "tensão" (strain) (STOGNER, 2020, p. 718-730), sendo bastante razoável esperar que indivíduos e corporações passem a recorrer a oportunidades ilegítimas para a prática de crimes e infrações econômicas (STICKLE; FELSON, 2020, p. 525-536). Aumenta-se a tolerância de risco e, consequentemente, a normalização de novos riscos se transforma em normalização de estado permanente de crise $^{13}$.

Howard Kunreuther e Michael Useem discutiram os mecanismos básicos de gestão de desastres e reorganização das estruturas de governança da empresa, especialmente no que diz respeito à distribuição dos recursos entre as vítimas (KUNREUTHER; USEEM, 2018, p. 126-132; KUNREUTHER; USEEM, 2010, p. 249; WHITE; LANG, 2012), e, com reflexo da COVID-19, especialização de estratégias de auditoria e due diligence sobre a "preparação" da empresa para o contexto de crise. Mesmo assim, a incompreensão dos processos de normalização traz como consequência natural a falsa percepção do controle. A ampla revisão do controle social dos negócios deve permitir superar não apenas as modalidades tradicionais da criação de falsos (positivos e negativos) produzidos na análise de risco regulatório, mas também - e sobretudo - em relação ao controle das incertezas e contingências produzidas em função do contexto da pandemia.

\footnotetext{
${ }^{13}$ Clássico o estudo em sociologia das organizações realizado por Diane Vaughan, na NASA. Vaughan analisa o acidente da nave espacial "Challenger" (1986), a partir do qual observou o fato de que tolerância a novos níveis de risco levaria a "normalidade do comportamento desviante" (normalisation of deviance) (VAUGHAN, 1989, p. 330-349).
} 


\section{RECONSTRUÇÃO SOCIAL PÓS-CRISE}

Seria uma saída demasiado simplista - e, em alguns casos, poderia não passar de uma convincente estratégia de consolidação de negócios advindos de práticas disruptivas trazidas pela pandemia (KNOWLEDGE AT WHARTON, 2020) - reorientar a atividade empresarial em benefício dos stakeholders. A reconstrução social pós-crise inspira, na verdade, reflexões sobre o papel da ética empresarial na própria gestão de crise, permitindo rever os fundamentos da moralidade corporativa e a extensão do que se entende por propósito e comportamento corporativo socialmente responsável.

A lógica da reconstrução social dispensa maior complexidade. Trata-se de atitudes bem básicas, orientadas pela compreensão do sentido das interações sociais entre pessoas, corporações e autoridades públicas (BRAITHWAITE, 2014, p. 1-17). É justamente este sentido que permite encontrar os limites de legitimação da moralidade corporativa e orientar o juízo sobre a necessidade e a efetividade dos programas de compliance, com a priorização do emprego dos recuros para a geração de oportunidades éticas e sustentáveis.

As dificuldades são muitas. Por um lado, parte da população que deveria ser financeiramente capaz de cumprir as medidas de distanciamento social está seguindo o exemplo dado pelo Presidente e ignorando todas as recomendações. Com a propagação da pandemia no Brasil, uma parte significativa dos apoiadores de Bolsonaro se uniu aos protestos (WP, 2020) contra os governadores dos estados e o Supremo Tribunal Federal este último por se oporem a Bolsonaro e reafirmarem o poder dos estados e municípios no federalismo brasileiro. Estes protestos foram apoiados por parte da população devido a informações enganosas disseminadas por altos níveis do Governo Federal, o que acabou prejudicando os esforços locais para conter a pandemia com base em dados científicos e nas diretrizes da Organização Mundial da Saúde.

Por outro, a desorganização social das grandes comunidades tornou simplesmente impraticável cumprir o discurso do "\#ficaemcasa" (VAN ROOIJ et al., 2020, p. 1-41). A análise da demografia brasileira também é essencial para entender a alta taxa de transmissão do Covid-19. Embora exista uma infraestrutura para viagens interestaduais e internacionais no país, várias regiões não têm um nível mínimo de desenvolvimento para implementar medidas de prevenção, muito menos para manter o distanciamento social da 
população. Como tal, os números do Covid-19 refletem a desigualdade brasileira, considerando que uma parte significativa da população não tem condições de ficar isolada em casa e ser protegida contra o vírus. O Governo Federal implementou um marco regulatório de assistência social para auxiliar financeiramente os idosos aposentados, os desempregados e os desprivilegiados registrados na Plataforma de Proteção Social (Cadastro Único Federal). No entanto, o marco ainda não conseguiu prover as pessoas não contabilizadas no sistema. Somente na região norte do Brasil, onde a saúde foi a primeira a entrar em colapso, pelo menos 1 milhão (PODER 360, 2020) de pessoas não tem acesso à eletricidade e cerca de 46 milhões $(G 1,2020)$ de pessoas no Brasil ainda não têm acesso à internet em 2020. Com tais limitações, essas pessoas enfrentam lutas adicionais para se cadastrar na Plataforma de Proteção Social e para serem assistidas pelo governo. Além disso, quase 35 milhões de pessoas no Brasil não tem acesso à água potável, por isso mal conseguem cumprir a recomendação primária contra o Covid-19 sem sair de casa.

O que importa mesmo no uso de recursos corporativos para fins de reconstrução social pós-conflito é que as corporações estejam moralmente abertas (FISSE; BRAITHWAITE, 1993, p. 218). É o que permite o desenvolvimento de sistemas de auto-avaliação confiáveis, restabelecendo os ambientes socialmente desintegrados (desmanche da cadeia de produção, desestruturação dos mercados, falta de accountability nas redes contratuais de emergência). Este seria o caminho preferencial para que as empresas, desde novas percepções sobre a liderança, pudessem articular novos vínculos com autoridades públicas reguladoras e fiscalizadoras (LAUFER, 2018). Ao menos se for mesmo o caso de uma expressão mais autêntica (LAUFER, 2017) das estratégias de gestão de crise como parte essencial dos programas de compliance.

\section{CONCLUSÕES}

Os efeitos adversos da regressão regulatória impostos pela política regulatória no Brasil agravam significativamente as crises sanitárias e econômicas provocadas pela Covid19. Apesar disso, as iniciativas corporativas de exercício do controle social são muito pouco significativas, limitando-se à reorganização interna das empresas diante das práticas disruptivas trazidas pelo contexto de pandemia. A seu modo, os programas de compliance 
não são necessários se não expressam o comportamento ético da empresa, ou se outros controles já funcionam e já, a seu modo, permitem expressar comportamento ético.

A crise da Covid-19 inova nos programas de compliance por exigir mais consistente articulação com a necessidade de preparação para a recondução da cadeia produtiva, das estruturas de mercado e das redes contratuais em relação ao que é de fato essencial. No entanto, os custos em compliance são dispensáveis, sobretudo em contexto de escassez de recursos, se não são estruturados como solução alternativa para a gestão da crise. E nem mesmo se a gestão de crise não estiver conduzida pela lógica da reconstrução social pósconflito, utilizando os recursos corporativos para restabelecer as interações sociais entre pessoas, corporações e autoridades públicas. O vácuo moral nas estratégias regulatórias do Covid-19 e as rupturas nas estruturas de mercado já estão aumentando os níveis de marginalização, pobreza extrema e violência entre nós e é precisamente aí que deveria incidir a priorização do emprego dos recuros para a geração de oportunidades éticas e sustentáveis.

Programa de compliance orientado por gestão de crise efetiva é a oportunidade histórica para o exercício de liderança transformativa e da revisão ética do papel do setor privado na consolidação das estruturas normativas de integridade da sociedade brasileira. Do contrário, o emprego de recursos de compliance com base na normalização de estado permanente de crises não deve ir para muito além do business as normal.

\section{REFERÊNCIAS}

AGOSTINE, Cristiane; BITENCOURT, Rafael; MURAKAWA, Fabio. Nelson Teich, ministro da Saúde, pede demissão do governo Bolsonaro. Valor Econômico, 2020. Disponível em: https://valor.globo.com/politica/noticia/2020/05/15/nelson-teich-ministro-da-saude-pededemissao.ghtml. Acesso em: 12 jul. 2020.

ALVES, Domingos et al. Estimativa de Casos de COVID-1". FAPESP, 2020. Disponível em: http://agencia.fapesp.br/pesquisadores-estimam-haver-mais-de-16-milhao-de-casos-deCovid-19-no-brasil/33116/. Acesso em: 12 jul. 2020.

AMARAL, Marina. Aumento de mortalidade no país está diretamente ligado a corte de verbas no SUS. Instituto Humanitas Unisinos, 2019. Disponível em: 
http://www.ihu.unisinos.br/78-noticias/594394-aumento-de-mortalidade-no-pais-estadiretamente-ligado-a-corte-de-verbas-no-sus. Acesso em: 10 jul. 2020.

ANAMATRA. "Anamatra se manifesta sobre o teor da MP 927/2020". Associação Nacional dos Magistrados da Justiça do Trabalho, 2020. Disponível em: https://www.anamatra.org.br/imprensa/noticias/29459-anamatra-se-manifesta-sobre-oteor-da-mp-927-2020. Acesso em: 18 jul. 2020.

AQUINO, Vanessa; MONTEIRO, Natália. Brasil confirma primeiro caso da doença. Ministério da Saúde, 2020. Disponível em: https://www.saude.gov.br/noticias/agenciasaude/46435-brasil-confirma-primeiro-caso-de-novo-coronavirus. Acesso em: 12 jul. 2020.

BBC. WHO head: 'Our key message is: test, test, test. BBC, 2020. Disponível em: https://www.bbc.com/news/av/world-51916707/who-head-our-key-message-is-test-testtest. Acesso em: 12 jul. 2020.

BEHRING, Elaine R. Brasil em contra-reforma: desestruturação do Estado e perda de direitos. São Paulo: Cortez, 2003.

BOA VISTA SCPC. Falências e Recuperações Judiciais. Boa Vista SCPC, 2020. Disponível em: https://www.boavistaservicos.com.br/economia/falencias-e-recuperacoes-judiciais/.

Acesso em: 22 jul. 2020.

BORLINI, Leandra M. Há pedras no meio caminho do SUS: os impactos do neoliberalismo na saúde do Brasil. Textos \& Contextos, Porto Alegre, v. 9, n. 2, 2010.

BRAITHWAITE, John. In praise of tents: regulatory studies and transformative social science. Annual Review of Law and Social Science, n. 10, p. 1-17, 2014.

BRAVO, Maria I. S. Serviço social e reforma sanitária: lutas sociais e práticas profissionais. 4. ed. São Paulo: Cortez, 2011.

CASA CIVIL. Notícias 2020. Governo Federal, 2020. Disponível em: https://www.gov.br/casacivil/pt-br/assuntos/noticias/2020. Acesso em: 18 jul. 2020.

CARAM, Bernardo; SALDAÑA, Paulo. Bolsonaro ataca STF e participa de aglomeração com faixas contra Congresso e Judiciário. Folha de S. Paulo, 2020. Disponível em: https://www1.folha.uol.com.br/poder/2020/05/bolsonaro-rebate-stf-descumpre-regrada-pandemia-e-participa-de-aglomeracao-com-faixas-contra-congresso-e-judiciario.shtml. Acesso em: 10 jul. 2020.

CONSELHO NACIONAL DE SAÚDE. Saúde perdeu R\$ 20 bilhões em 2019 por causa da EC 95/2016. Ministério da Saúde. Disponível em: https://conselho.saude.gov.br/ultimasnoticias-cns/1044-saude-perdeu-r-20-bilhoes-em-2019-por-causa-da-ec-95-2016. Acesso em: 10 jul. 2020.

CORONAVIRUS RESOURCE CENTER. New Cases of COVID-19 In World Countries. Johns Hopkins University \&b Medicine. Disponível em: https://coronavirus.jhu.edu/data/newcases. Acesso em: 22 jul. 2020.

D'AGOSTINO, Rosanne. Supremo não tirou do governo federal responsabilidades por crise do coronavírus, diz Fux. G1, 2020. Disponível em: https://g1.globo.com/politica/noticia 
/2020/06/22/stf-nao-exonerou-executivo-federal-de-responsabilidade-por-pandemia-dizfux.ghtml. Acesso em: 18 jul. 2020.

DELATORRE, Edson et al. Tracking the onset date of the community spread of SARS-CoV-2 in Western Countries. Memórias do Instituto Oswaldo Cruz. Journal of microbes \& their vectors causing human infections, 2020. Disponível em: https://memorias.ioc.fiocruz.br/article/10702/0183-tracking-the-onset-date-of-thecommunity-spread-of-sars-cov-2-in-western-countries. Acesso em: 12 jul. 2020.

FERREIRA, Gustavo; FILGUEIRAS, Isabel. O que é circuit breaker? Saiba porque a B3 para quando o Ibovespa cai 10\%. Valor Investe, 2020. Disponível em: https://valorinveste.globo.com/mercados/renda-variavel/bolsas-eindices/noticia/2020/03/18/o-que-e-circuit-breaker-saiba-porque-a-b3-para-quando-oibovespa-cai-10percent.ghtml. Acesso em: 22 jul. 2020.

FISSE, Brent; BRAITHWAITE, John. Corporations, crime and accountability. Cambridge: Cambridge Press, 1993.

FONSECA, Hugo. Coronavírus escancara precarização do trabalho de entregadores de delivery. Estadão, 2020. Disponivel em: https://politica.estadao.com.br/blogs/faustomacedo/coronavirus-escancara-precarizacao-do-trabalho-de-entregadores-de-delivery/.

Acesso em: 13 jul. 2020.

FREITAS, Carlos M. de (coord.). A gestão de riscos e governança na pandemia por COVID-19 no Brasil: análise dos decretos estaduais no primeiro mês: relatório técnico e sumário executivo. Fundação Oswaldo Cruz, 2020. Disponível em: https://www.arca.fiocruz.br/handle/icict/41452. Acesso em: 22 jul. 2020.

FRIEDRICHS, David O.; ROTHE, Dawn L. Regulatory rollback and white-collar crime in the era of Trump: the challenges of perspective. Journal of White Collar and Corporate Crime, v. 1, n. 2, 2020.

GARCIA, Diego. Pandemia aniquilou 7,8 milhões de postos de trabalho no Brasil. Folha de S. Paulo, 2020. Disponível em: https://www1.folha.uol.com.br/mercado/2020/06/desemprego-chega-a-129-em-meio-apandemia-da-Covid-19.shtml. Acesso em: 10 jul. 2020.

GARCIA, Raphael T. Bolsonaro's Social Media War With the Press Keeps Bleeding Into the Real World. Slate, 2020. Disponível em: https://slate.com/technology/2020/07/brazilpresident-bolsonaro-attacks-press-journalists.html. Acesso em: 10 jul. 2020.

HAASS, Richard N. The politics of a COVID-19 Vaccine. Project Syndicate, 14.07.2020.

HABERMAS, Jürgen. Interview: Jürgen Habermas über Corona. Frankfurter Rundschau, 10 abr. 2020.

HAN, Byung-Chul. O coronavírus de hoje e o mundo de amanhã. El País, 22 mar. 2020.

HARARI, Yuval Noah. The world after coronavirus. Financial Times, 04 nov. 2020.

IGLESIAS, Simone P.; ADGHIRNI, Samy. Brazil's State Governors Defy Bolsonaro in Coronavirus Fight. Bloomberg, 2020. Disponível em: 
https://www.bloomberg.com/news/articles/2020-03-25/brazilian-state-governors-defybolsonaro-in-coronavirus-fight. Acesso em: 12 jul. 2020.

IMPERIAL COLLEGE LONDON COVID-19 RESPONSE TEAM. Short-term forecasts of Covid-19 deaths in multiple countries. Imperial College London, 2020. Disponível em: https://mrcide.github.io/Covid19-short-term-forecasts/index.html. Acesso em: 12 jul. 2020.

KADANUS, Kelli. Placebo: tudo que se sabe sobre a operação quem tem Wilson Witzel como alvo. Gazeta do Povo, 2020. Disponível em: https://www.gazetadopovo.com.br/republica/placebo-witzel-governador-operacao-rio/. Acesso em: 12 jul. 2020.

KNOWLEDGE AT WHARTON. Coping with Coronavirus: five strategies to mitigate business risks, 17 maio 2020.

KNOWLEDGE AT WHARTON. Coronavirus and supply chain disruption: what firms can learn, 17 maio. 2020.

KPMG. COVID-19: Compliance Survey, 04 jun. 2020.

KUNREUTHER, Howard; USEEM, Michael. Mastering catastrophic risk: how companies are coping with disruption. Oxford: Oxford Press, 2018.

KUNREUTHER, Howard; USEEM, Michael. Learning from catastrophes: strategies for reaction and response. New Jersey: Pearson, 2010

LAUFER, William. A very special regulatory milestone. University of Pennsylvania Journal of Business Law, n. 391, 2018.

LAUFER, William. The missing account of Progressive Corporate Criminal Law. New York University Journal of Law and Business, v. 14, n. 1, p. 1-63, 2017.

LUPION, Bruno. Por que o Brasil testa tão pouco para Covid-19. DW, 2020. Disponível em: https://www.dw.com/pt-br/por-que-o-brasil-testa-t\%C3\%A3o-pouco-para-Covid-19/a53222194. Acesso em: 12 jul. 2020.

MAIEROVITCH, Cláudio; VASQUEZ, Enrique. A resposta do Sistema Único de Saúde à epidemia de Zika. In: ORGANIZAÇÃO PAN-AMERICANA DA SAÚDE. Relatório 30 anos de SUS, que SUS para 2030?, 2018.

MENDES, Áquilas. Tempos turbulentos na saúde pública brasileira: impasses do financiamento no capitalismo financeirizado. São Paulo: Hucitec, 2012.

MICHALOWSKI, Raymond; BROWN, Meredith. Old wine, new bottles: contextualizing Trump's regulatory rollback. Explorations in Critical Criminology in Honor of William J. Chambliss. Leiden: Koninklijke Brill NV, 2019.

MINISTÉRIO DA ECONOMIA. Nota Informativa - Impactos Econômicos da COVID-19 (13/05/2020). Governo Federal, 2020. Disponível em: https://www.gov.br/economia/ptbr/centrais-de-conteudo/publicacoes/notas-informativas/2020/nota-impactoseconomicos-da-Covid-19.pdf/view. Acesso em: 02 jul. 2020.

NORONHA, José C.; SOARES, Laura T. A política de saúde no Brasil nos anos 90. Ciênc. Saúde coletiva, São Paulo, v. 6, n. 2, 2001. 
OCAMPO, José Antonio; FACCIO, Tommaso. Making Multinationals and the wealthy pay. Project Syndicate, 30 jun. 2020.

OLIVEIRA, Rodrigo F. A contra-reforma do Estado no Brasil: uma análise crítica. Revista Urutágua, v. 24, 2011.

ORGANIZAÇÃO MUNDIAL DA SAÚDE. Brazil highlights treatment for all people with HIV. World Health Organization, $2018 . \quad$ Disponível em: https://www.who.int/hiv/mediacentre/news/brazil-hiv-treatment-all-plhiv/en/. Acesso em: 18 jun. 2020.

ORGANIZAÇÃO MUNDIAL DA SAÚDE. WHO Director-General's opening remarks at the media briefing on Covid-19 - 11 March 2020. World Health Organization, 2020. Disponível em: https://www.who.int/dg/speeches/detail/who-director-general-s-opening-remarks-atthe-media-briefing-on-Covid-19---11-march-2020. Acesso: 15 jun. 2020.

PAIVA, Carlos H. A.; TEIXEIRA, Luiz A. Reforma sanitária e a criação do Sistema Único de Saúde: notas sobre contextos e autores. História, Ciências, Saúde - Manguinhos, v.21, n.1, 2014.

PAULINO, Luís A. A pandemia e os seus impactos políticos e econômicos. In: CORSI, Francisco L.; DOS SANTOS, Agnaldo (org.). Os rumos do Brasil e da América Latina. Bauru: Ed. Canal 6 Editora, 2020.

PESSANHA, Maure et al. A vulnerabilidade dos informais: um desafio anterior à Covid-19. Folha de S. Paulo, $2020 . \quad$ Disponível em: https://www1.folha.uol.com.br/empreendedorsocial/2020/06/a-vulnerabilidade-dosinformais-um-desafio-anterior-a-Covid-19.shtml. Acesso em: 13 jul. 2020.

PHILLIPS, Tom. Brazil's Jair Bolsonaro says coronavirus crisis is a media trick. The Guardian, 2020. Disponível em: https://www.theguardian.com/world/2020/mar/23/brazils-jairbolsonaro-says-coronavirus-crisis-is-a-media-trick. Acesso em: 18 jun. 2020.

PHILLIPS, Tom. Bolsonaro ignored by state governors amid anger at handling of Covid-19 crisis. The Guardian, $2020 . \quad$ Disponível em: https://www.theguardian.com/world/2020/apr/01/brazil-bolsonaro-ignored-by-stategovernors-amid-anger-at-handling-of-Covid-19-crisis. Acesso em: 12 jul. 2020.

PIRES, Carol. A maior tragédia do coronavírus pode ser nas favelas brasileiras. The New York Times, 2020. Disponível em: https://www.nytimes.com/pt/2020/03/31/espanol/opinion/a-maior-tragedia-docoronavirus-pode-ser-nas-favelas-brasileiras.html. Acesso em: 10 jun. 2020.

REN, Xuefei. Pandemic and lockdown: a territorial approach to COVID-19 in China, Italy and the United States. Eurasian Geography and Economics, 2020. Disponível em: https://rsa.tandfonline.com/doi/full/10.1080/15387216.2020.1762103?scroll=top\&needA ccess=true\#.XxSPI55Kg2w. Acesso em: 18 jul. 2020.

RICARD, J., MEDEIROS, J. Using misinformation as a political weapon: Covid-19 and Bolsonaro in Brazil. The Harvard Kennedy School (HKS) Misinformation Review, v. 1, n. 2, 2020. 
SANT'ANA, Jessica. A reforma tributária do coronavírus: como a pandemia mudou (e ainda pode mudar) os impostos. Gazeta do Povo, 2020. Disponível em: https://www.gazetadopovo.com.br/republica/a-reforma-tributaria-do-coronavirus-comoa-pandemia-mudou-e-ainda-pode-mudar-os-impostos/. Acesso em: 18 jul. 2020.

SHALDERS, André. Mandetta é demitido do Ministério da Saúde após um mês de conflito com Bolsonaro: relembre os principais choques. BBC Brasil, 2020. Disponível em: https://www.bbc.com/portuguese/internacional-52316728. Acesso em: 13 jul. 2020.

SHALDERS, André. Coronavírus: governadores são principais rivais de Bolsonaro nas redes, diz levantamento. BBC Brasil, $2020 . \quad$ Disponível em: https://www.bbc.com/portuguese/brasil-52192736. Acesso em: 29 jun. 2020.

SILVA, Ilse G. Democracia e participação na “Reforma do Estado". São Paulo: Cortez, 2003.

SOARES, Raquel C. A racionalidade da contrarreforma na política de saúde e o serviço social. In: BRAVO, Maria I. S.; MENEZES, Juliana S. B. (org.). Saúde, serviço social, movimentos sociais e conselhos: desafios atuais. 2. ed. São Paulo: Cortez, 2013.

SOUZA, Bruna B et al. A Política de AIDS no Brasil: uma abordagem histórica. Journal of Management \& Primary Health Care: Usuário, informações, natureza e a Atenção Primária à Saúde, v. 1, n. 1, 2010.

SOUZA, Renilson R. et al. Trinta anos do Sistema Único de Saúde brasileiro Sustentabilidade e desafios: perceções de atores estratégicos. Políticas, Sistemas e Serviços de Saúde - 5ํ Congresso Nacional de Medicina Tropical, v. 18, 2019.

STICKLE, Ben; FELSON, Marcus. Crimes rates in a Pandemic: the largest criminological experiment in History. American Journal of Criminal Justice, v. 25, p. 525-536, 2020.

STIGLITZ, Joseph. Priorities for the COVID-19 economy. Project Syndicate, 01 jul. 2020.

STOGNER, John et al. Police stress, mental health, and resiliency during the COVID-19 Pandemic. American Journal of Criminal Justice, v. 45, p. 718-730, 2020.

STF. AÇÃO DIRETA DE INCONSTITUCIONALIDADE: ADI 6341. Relator: Ministro Marco Aurélio. Supremo Tribunal Federal, 2020. Disponível em: https://portal.stf.jus.br/processos/detalhe.asp?incidente=5880765. Acesso em: 18 jul. 2020.

TIEDEMANN, Klaus. Zur Kultur der Unternehmensstrafbarkeit. In: QUELOS, Nicolas (org.) Droit penal et diversités culturelles - Festschrift für José Hurtado Pozo. Basel: Schulthess, 2012, p. 495-512.

THE INTERCEPT. Bancos travam bilhões liberados pelo governo para salvar microempresários na crise do coronavirus, 18 maio 2020.

THE NEW YORK TIMES. Brazil Coronavirus Map and Case Count. The New York Times, 2020. Disponível em: https://www.nytimes.com/interactive/2020/world/americas/brazilcoronavirus-cases.html. Acesso em: 31 jul. 2020.

URIBE, Gustavo; CHAIB, Julia; COLETTA, Ricardo D. "Não vai ser uma gripezinha que vai me derrubar", diz Bolsonaro sobre coronavírus. Folha de S. Paulo, 2020. Disponível em: 
https://www1.folha.uol.com.br/poder/2020/03/nao-vai-ser-uma-gripezinha-que-vai-mederrubar-diz-bolsonaro-sobre-coronavirus.shtml. Acesso em: 13 jul. 2020.

VAN ROOIJ, Benjamin et al. Compliance with COVID-19 mitigation measures in the United States. Amsterdam Law School Research Paper, n. 21, p. 1-41. 2020

VAUGHAN, Diane. Regulating risk: implications of the Challenger accident. Law and Policy, v. 11, p. 330-349, 1989.

WHITE, Stacey; LANG, Hardin. Corporate engagement in natural disaster response: piecing together the value chain. Washington: CSIS, 2012.

DINIZ, Eduardo Saad; URBAN, Mariana. Compliance e gestão de crise da COVID-19: política regulatória e

reconstrução social pós-conflito. RBSD - Revista Brasileira de Sociologia do Direito, v. 8, n. 1, p. 172-195, jan./abr. 2021. 